\title{
Modul Komunikasi Modbus RTU over RS485 Berbasis Arduino
}

\author{
Indra H Mulyadi ${ }^{*}$, Rahmi Mahdaliza ${ }^{1}$, Aditya Gautama ${ }^{1}$, Senanjung Prayoga ${ }^{1}$, Kamarudin ${ }^{1}$ \\ ${ }^{1}$ Politeknik Negeri Batam, Batam, Indonesia \\ *Email: indra@polibatam.ac.id
}

\begin{abstract}
Modul akuisisi data dengan menggunakan Modbus Remote Terminal Unit (RTU) telah banyak digunakan secara komersial di industri. Namun sayangnya, harga peralatan tersebut tergolong mahal. Protokol komunikasi Modbus RTU ini cukup kompleks untuk dibuat oleh pengguna awam. Dengan latar belakang tersebut, penelitian ini bertujuan untuk membuat modul komunikasi Modbus RTU over RS485 yang berbasiskan Arduino sehingga harga pembuatannya menjadi murah dan dapat menjadi sarana pembelajaran di lembaga pendidikan dan pelatihan. Modul yang dibuat ini terdiri atas dua input analog dan dua input/output digital. Sinyal analog yang masuk dikondisikan terlebih dahulu dengan menggunakan signal conditioner sebelum diproses lebih lanjut oleh mikrokontroler. Hasil pengujian menggunakan Modbus Analyzer menunjukkan bahwa komunikasi Modbus RTU over RS485 pada modul yang telah dibuat ini dapat berjalan sesuai dengan data frame yang didesain.
\end{abstract}

Kata kunci: Modbus RTU, RS485, Arduino

\section{Pendahuluan}

DALAM sebuah plant kontrol proses, pengukuran dilakukan untuk memonitor beberapa besaran, seperti tekanan, level, aliran, dan suhu. Proses pengukuran besaran-besaran tersebut merupakan proses akuisisi data. Akuisisi data yang dilakukan dalam lingkunan industri tentunya tidak sederhana, mengingat data yang diakuisisi cukup banyak dan jarak antara sensor yang satu dan lainnya berjauhan.

Salah satu sistem monitoring yang digunakan di industri adalah Supervisory Control and Data Acquisition (SCADA) [1]-[3]. Membangun sistem SCADA berarti membangun jaringan komunikasi dan Human Machine Interface (HMI) [4]. Data dari sensor pada sebuah plant diakuisisi dan dikirimkan ke komputer menggunakan modul komunikasi, baik menggunakan kabel maupun nirkabel.

Peralatan-peralatan yang ada dalam sebuah sistem SCADA seperti Programmable Logic Controller (PLC), HMI, control panel, driver, kendali motor, dan Input/Output (I/O) mengunakan protokol komunikasi dalam untuk pengiriman data. Ada beberapa jenis protokol komunikasi untuk menghubungkan peralatan yang ada di dalam sebuah sistem SCADA, seperti Modbus, RP-570, Profibus, dan Conitel [5]. Protokol yang digunakan dalam penelitian ini adalah Modbus, sebuah protokol yang banyak digunakan pada instrumentasi di industri. Ada beberapa jenis Modbus yang dipakai di industri, antara lain Modbus RTU, Modbus ASCII, Modbus TCP/IP, Modbus UDP/IP, Pemex Modbus, Daniel Modbus, dan Enron Modbus. Modbus yang digunakan pada penelitian ini adalah Modbus RTU.

Pada OSI layer, Modbus [6] merupakan protokol komunikasi yang terletak pada application layer, yakni pada level 7. Layer ini yang menyediakan komunikasi client/server antar peralatan yang saling terkoneksi dengan tipe bus dan jaringan yang berbeda.

Modbus bekerja berdasakan pola request/reply. Request dilakukan oleh alat yang berperan sebagai master; sedangkan reply dilakukan oleh alat yang berperan sebagai slave. Secara umum, satu frame paket data Modbus terdiri atas Protocol Data Unit (PDU) dan Application Data Unit (ADU). PDU terdiri atas function code dan data, sedangkan ADU terdiri atas PDU ditambah address dan error check.

Secara de facto, Modbus mulai dipakai sejak 1979. Saat ini, jutaan peralatan otomasi mengunakan protokol ini. Beberapa peralatan peralatan dalam sistem SCADA seperti PLC, HMI, Control panel, driver, kendali motor, dan I/O menggunakan protokol Modbus ini untuk saling terhubung jarak jauh. Agar dapat digunakan pada jarak hingga lebih dari $1 \mathrm{~km}$, maka modul yang dibuat pada penelitian ini menggunakan RS485 [7].

Modul akuisisi data dengan menggunakan Modbus RTU telah banyak digunakan di industri. Namun sayangnya, harga peralatan tersebut tergolong mahal. Protokol komunikasi Modbus RTU cukup kompleks untuk dibuat oleh pengguna awam. Dengan latar belakang itulah penelitian ini membuat modul komunikasi Modbus RTU over RS485 yang berbasiskan Arduino sehingga harga pembuatannya menjadi murah, di samping dapat menjadi pembelajaran bagi pengguna awam, seperti lembaga pendidikan dan pelatihan.

\section{Metode}

\section{A. Perancangan Elektronik}

Diagram blok sistem elektronik pada modul yang dibuat ini dapat dilihat pada Gambar 1. Input analog terdiri atas 2 channel. Digital input/output terdiri atas 2 channel. Sebelum masuk ke 
Analog-to-Digital converter (ADC) milik Arduino, sinyal analog dimasukkan terlebih dahulu ke signal conditioner berupa pembagi tegangan, dioda Zener, dan kapasitor. Hal ini berfungsi untuk filtering sinyal yang masuk dan mencegah over voltage. Gambar 2 memperlihatkan layout Printed Circuit Board (PCB) yang dibuat. PCB ini bersifat plug-and-play untuk dipasang di atas Arduino Uno (menjadi Arduino shield).
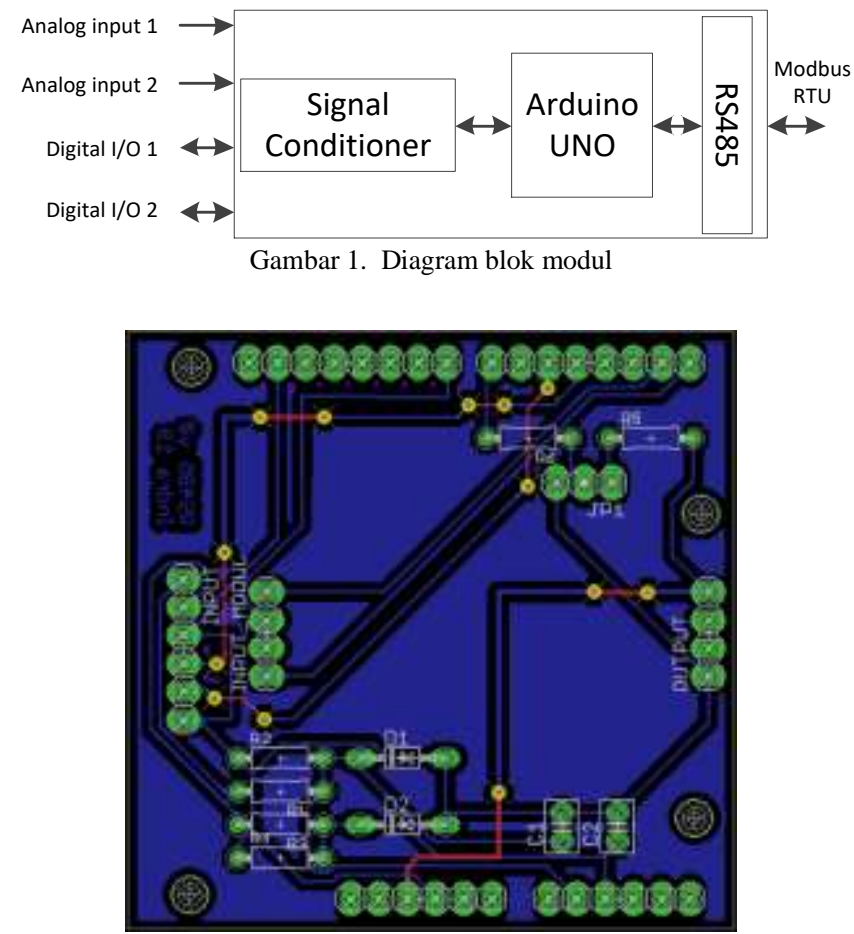

Gambar 2. Layout PCB

Modul ini dilengkapi dengan dua buah Light Emitting Diode (LED). LED berwarna merah adalah indikasi power, yang akan menyala ketika ada power yang masuk. LED berwarna biru adalah indikator yang akan memberitahukan bahwa komunikasi antara Modbus slave dan Modbus master sedang berlangsung.

\section{B. Perancangan Mekanik}

Gambar 3 menunjukkan desain casing yang dibuat menggunakan 123D Design (Autodesk, San Rafael, Amerika Serikat), sebuah perangkat lunak gratis untuk desain tigadimensi (3D). Pembuatan casing dilakukan menggunakan mesin 3D printer.

Gambar 4 menunjukkan konektor untuk akuisisi data dan koneksi untuk komunikasi menggunakan RS485. Konektor untuk akuisisi data terdiri atas enam pin (analog input \#1, analog input \#2, digital I/O \#1, digital I/O \#2, dan dua ground). Selain itu ditambahkan pula dua pin untuk input suplai 7 12 VDC. Konektor untuk komunikasi terdiri atas tiga pin, yakni A, B, dan GND, sesuai dengan standar RS485. Gambar 5 memperlihatkan modul yang telah dibuat. Modul ini diberi nama MR48519A.

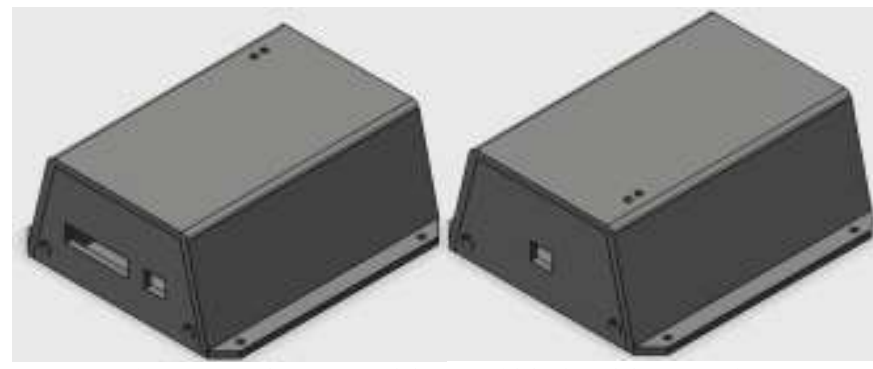

Gambar 3. Desain casing: sisi input (kiri) dan sisi output (kanan)

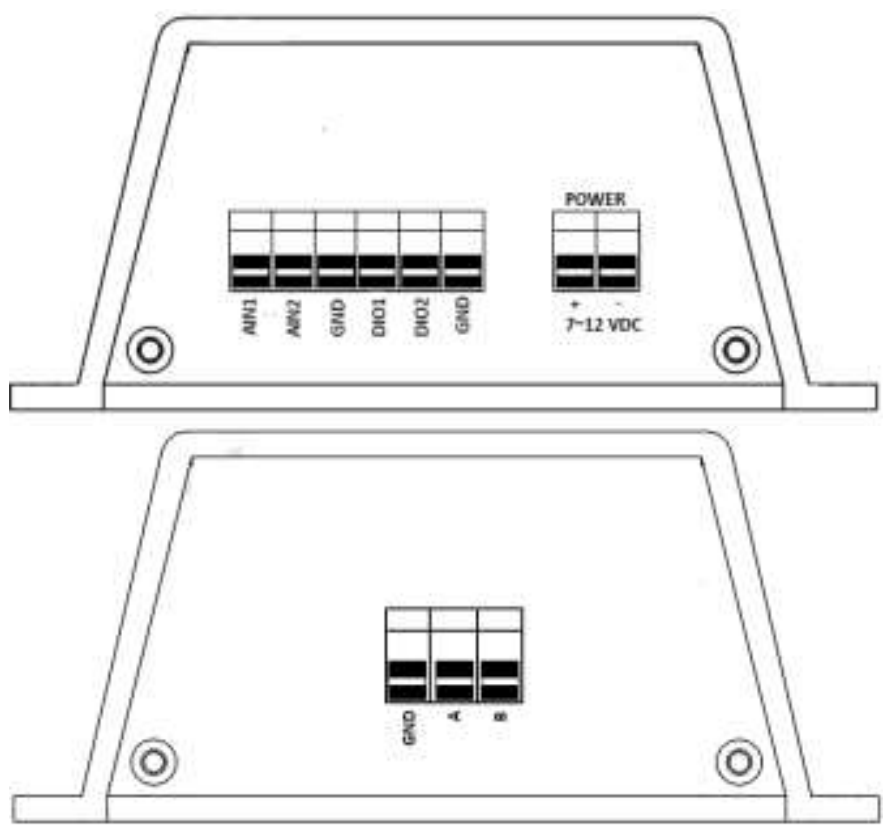

Gambar 4. Konektor untuk akuisisi data (atas) dan konektor untuk komunikasi menggunakan RS485 (bawah)
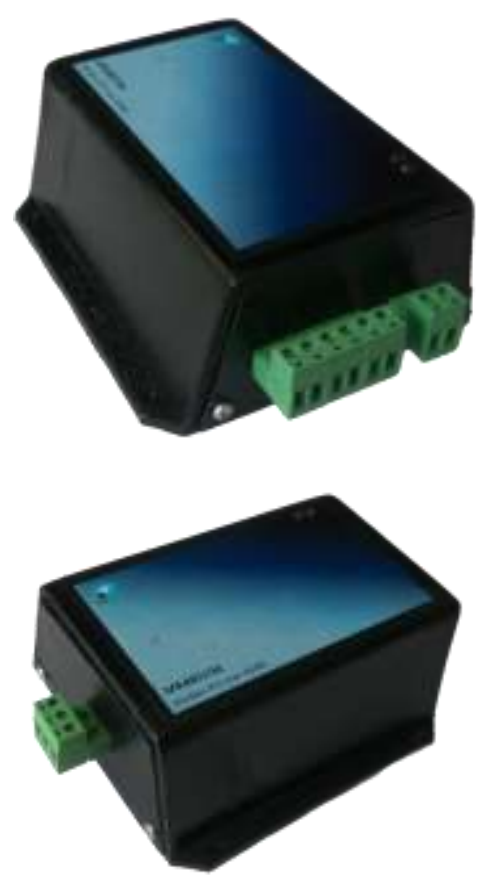

Gambar 5. Modul MR48519A 


\section{Data Frame}

Modul RTU yang dibuat ini berperan sebagai Modbus slave dengan data frame sesuai pada Gambar 6. Data frame terdiri atas slave ID, function code, panjang data, data, dan Cyclic Redundancy Check (CRC). Slave ID pada penelitian ini diset 0x01, function code yang digunakan adalah 0x03 (read holding registers). Panjang data adalah 8 byte. Data terdiri atas input analog (4 byte) dan input/output digital (4 byte). Data analog menggunakan dua channel. Masing-masing channel memerlukan 2 byte, sehingga total data yang diperlukan untuk membaca data analog adalah 4 byte. Data digital merupakan dua channel input/output yang masing-masing menggunakan 2 byte, sehingga total alokasi yang diperlukan untuk data digital adalah 4 byte. Paket terakhir adalah CRC-16 (2 byte).

\begin{tabular}{|c|c|c|c|c|}
\hline $\begin{array}{c}\text { Slave } \\
\text { ID }\end{array}$ & $\begin{array}{c}\text { Function } \\
\text { Code }\end{array}$ & $\begin{array}{c}\text { Panjang } \\
\text { data }\end{array}$ & $\begin{array}{c}\text { data } \\
(4 \times 2 \text { byte })\end{array}$ & CRC-16 \\
\hline
\end{tabular}

Gambar 6. Data frame Modbus RTU

\section{HASIL DAN PEMBAHASAN}

Pada pengujian ini, kami menggunakan perangkat lunak ModbusMAT v1.1, sebuah Modbus analyzer yang digunakan sebagai Modbus server. Cara kerja analyzer ini adalah memberikan perintah kepada Modbus slave dan membaca data yang masuk dari slave sebagaimana cara kerja standar sebuah Modbus server. Pengujian dilakukan dengan menghubungkan master dan slave menggunakan koneksi RS485. Pembacaan data dari modul slave dilakukan secara secara berkala per 1000 dan 500 ms. Perhatikan Gambar 7.

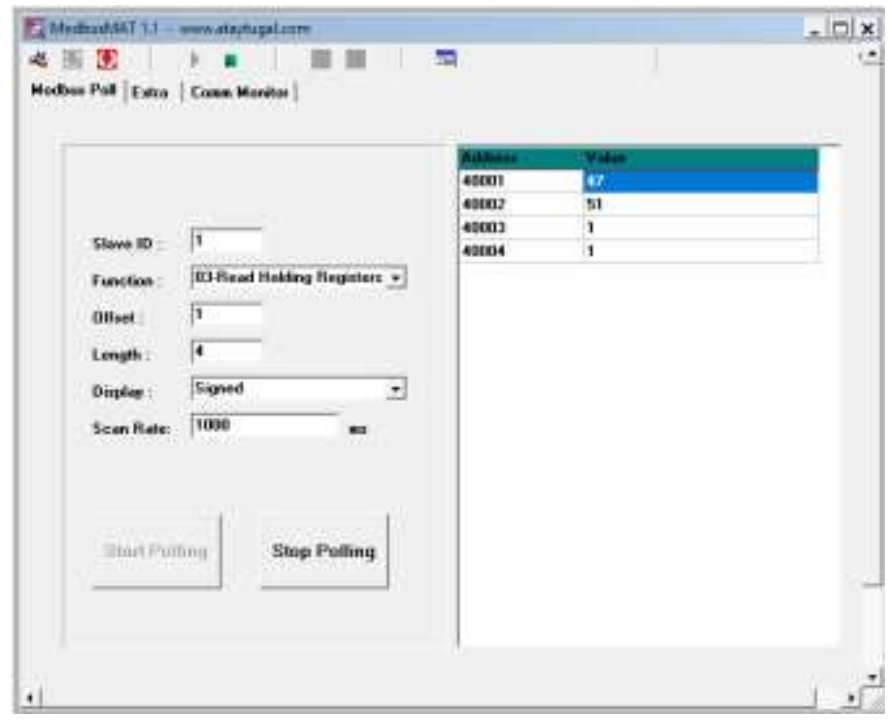

Gambar 7. Hasil pembacaan data yang masuk menggunakan Modbus RTU

ModbusMAT menyediakan menu port monitor untuk menganalisis aliran data, baik dari master ke slave maupun sebaliknya. Perhatikan Gambar 8. Data berwarna biru merupakan data dari master ke slave, sedangkan yang berwarna hitam adalah aliran data dari slave ke master.

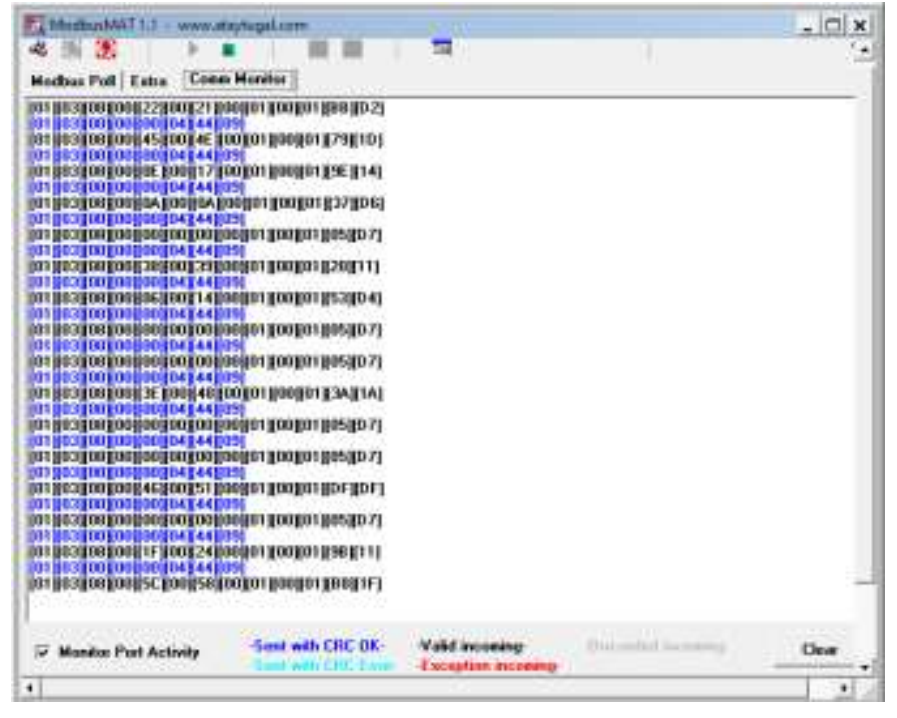

Gambar 8. Analisis data yang masuk menggunakan Modbus RTU

Sebagai contoh kasus, perhatikan baris ke-2 pada aliran data dalam Gambar 8, yakni 0x01, 0x03, 0x00, 0x00, 0x00, 0x04, 0x44, 0x09, yang merupakan data frame master-to-slave. Dengan menggunakan kalkulator, diperoleh CRC-16 dari 0x010300000004 adalah 0x0944. Hal ini sesuai dengan CRC16 pada data frame. Data frame master-to-slave ini diuraikan lebih detail dalam Tabel I.

TABEL I

DATA FRAME MASTER-TO-SLAVE

\begin{tabular}{cl}
\hline \hline Data frame & \multicolumn{1}{c}{ Keterangan } \\
\hline 0x01 & Slave ID = 1 \\
0x03 & Function code $=3$ (Read holding register) \\
0x00 & Data \\
0x00 & Data \\
0x00 & Data \\
0x04 & Data \\
0x44 & CRC-16=0x0944 \\
0x09 & \\
\hline \hline
\end{tabular}

TABEL II

DATA FRAME SLAVE-TO-MASTER

\begin{tabular}{cl}
\hline \hline Data frame & \multicolumn{1}{c}{ Keterangan } \\
\hline 0x01 & Slave ID $=1$ \\
0x03 & Function code $=3$ (Read holding register) \\
0x08 & Panjang data $=8$ byte \\
0x00 & Data \\
0x45 & Data \\
0x00 & Data \\
0x4E & Data \\
0x00 & Data \\
0x01 & Data \\
0x00 & Data \\
0x01 & Data \\
0x79 & CRC-16 = 0x1D79 \\
0x1D & \\
\hline \hline
\end{tabular}

Data frame pada Tabel I diterima oleh slave untuk diproses. Kemudian slave merespon dengan mengirimkan data frame ke master sesuai pada baris ke-3 pada aliran data dalam Gambar 8, yakni 0x01, 0x03, 0x08, 0x00, 0x45, 0x00, 0x4E, 0x00, 0x01, 0x00, 0x01, 0x79, 0x1D. Dengan menggunakan kalkulator, diperoleh CRC-16 dari 0x0103080045004E00010001 adalah 
0x1D79. Hal ini sesuai dengan CRC-16 pada data frame. Data frame slave-to-master ini diuraikan lebih detail dalam Tabel II.

Tabel I dan Tabel II menunjukkan bahwa Modbus master berhasil mengirimkan perintah ke slave dengan menggunakan data frame yang benar. Pada arah sebaliknya (slave-to-master), data (berupa analog dan digital) berhasil dikirimkan oleh slave ke Modbus master sesuai dengan data frame standar Modbus yang telah didesain. Perhitungan CRC-16 dapat dilakukan dengan tepat. Dengan demikian, dapat disimpulkan bahwa komunikasi Modbus berjalan sesuai dengan data frame yang didesain.

Modul yang dibuat ini masih dalam tahap pengembangan sehingga memiliki beberapa keterbatasan. Ke depannya, modifikasi protokol perlu dilakukan untuk memastikan data reliability. Pengujian jarak maksimal penggunaan modul ini perlu dilakukan sesuai dengan standar RS485. Safety dan performansi dari modul ini perlu diuji lebih lanjut sesuai Standar Nasional Indonesia (SNI) dan International Electrotechnical Commission (IEC). Kalibrasi juga perlu dilakukan untuk memastikan kebenaran pembacaan data.

\section{KESIMPULAN}

Modul Modbus RTU over RS485 berbasis Arduino telah dibuat. Modul ini berbiaya murah dan diharapkan sesuai untuk sarana pembelajaran bagi pengguna yang awam, seperti lembaga pendidikan dan pelatihan. Hasil pengujian menunjukkan bahwa komunikasi Modbus dapat berjalan sesuai dengan data frame yang didesain. Penelitian selanjutnya perlu dilakukan untuk memastikan data reliability. Pengujian jarak maksimal, safety, dan performansi dari modul ini perlu diuji lebih lanjut sesuai standar SNI dan IEC. Demikian halnya dengan proses kalibrasi.

\section{UCAPAN TERIMA KASIH}

Penelitian ini dibiayai oleh Pusat Penelitian dan Pengabdian Masyarakat Politeknik Negeri Batam melalui penelitan internal dengan skema Penelitian Madya.

\section{REFERENSI}

[1] D. Bailey and E. Wright, Practical SCADA for Industry. Burlington, USA: Elsevier, 2003.

[2] M. Bagajewicz, A. Fuxman, and A. Uribe, "Instrumentation network design and upgrade for process monitoring and fault detection," AIChE J., vol. 50, no. 8, pp. 1870-1880, Aug. 2004, doi: 10.1002/aic.10279.

[3] S. K. Mittal, M. Singh, P. Kapur, B. K. Sharma, and M. A. Shamshi, "Design and development of instrumentation network for landslide monitoring and issue an early warning," J. Sci. Ind. Res. (India)., vol. 67, no. 5, 2008.

[4] F. Ponci, A. Sadu, R. Uhl, M. Mirz, A. Angioni, and A. Monti, "Instrumentation and measurement testing in the real-Time lab for automation of complex power systems," IEEE Instrum. Meas. Mag., vol. 21, no. 1, 2018, doi: 10.1109/MIM.2018.8278805.

[5] D. J. Kang and R. J. Robles, "Compartmentalization of protocols in SCADA communication," Int. J. Adv. Sci. Technol., vol. 8, pp. 27-36, 2009.

[6] Modbus, Modbus. Hopkinton, MA, USA: Modbus Organization, Inc., 2012.

[7] RS-422 and RS-485 Applications Ebook: A Practical Guide to Using RS422 and RS-485 Serial Interfaces. Ottawa, Illinois, USA: Advantech B+B SmartWorx, 2010. 